\title{
A FEBRE AMARELA COMO JUSTIFICATIVA AO DERESPEITO À VIDA E AOS DIREITOS DOS ANIMAIS NÃO HUMANOS
}

Khetlen Eduarda Ferreira Marinho dos Santos; Fábio Ferreira Morong.

Universidade do Oeste Paulista- UNOESTE, Direito, Presidente Prudente - SP, e-mail: ke.tlen@hotmail.com

\section{RESUMO}

O recente surto da doença febre amarela do tipo silvestre, contribui à postura de autotutela por parte dos afetados que supõem que com a morte dos macacos, o contágio e o combate doença seriam solucionados. Entretanto, os símios, assim como os seres humanos, são vítimas da doença, que também pode matá-los. Por certo, não são agentes causadores, sendo o único transmissor o mosquito. $\mathrm{O}$ presente estudo pretende conscientizar os aplicadores do direito sobre o tema e desenvolver uma breve análise sobre o surto da doença e o aumento da matança de macacos. 0 método aplicado foi o dedutivo legal, baseado na interpretação da legislação, jurisprudências e doutrinas. Conclui-se que, por ser a referida doença infecciosa causada por um flavírus e ser transmitida em áreas florestais, principalmente pelo mosquito Haemagogus, os direitos dos macacos devem ser tutelados, eis que não são responsáveis diretos pelo contágio e, tais como os humanos, têm também o direito à vida.

Palavras-chave: Febre Amarela, Descoisificação, Direito dos Animais, Proteção Jurídica aos Animais, Senciência.

\section{YELLOW FEVER AS A REASON FOR THE LACK OF LIFE AND THE RIGTHS NON-HUMAN ANIMALS}

\begin{abstract}
The recent outbreak of the wild-type yellow fever disease contributes to the self-imposed stance of those affected who assume that if monkeys are killed, the contagion and disease combat would be solved. However, apes are victims of the disease, just like humans, which can also kill them. Increase of murders of monkeys, they are not disease causative agents and the only transmitter is mosquito. The present study aims to raise the awareness of law enforcers and to develop a substantial analysis of the outbreak of yellow fever and the increase in murders of monkeys. The applied method was the legal deductive, based on the interpretation of the legislation, jurisprudence and doctrines. It is concluded that the said infectious disease is caused by a flavirus and is transmitted in forest areas mainly by the Haemagogus mosquito of the genus Sabethes, so that the rights of the animals should be protected, since they, like humans, also have the right to life and protection and shouldn't it be treated as objects, but as a subject of rights.

Keywords: Yellow Fever, Descoisation, Animal Rights, Legal Protection of Animals, Sence.
\end{abstract}




\section{INTRODUÇÃO}

Recentemente, o Brasil foi inserido em um surto da doença da febre amarela e uma situação estarrecedora restou percebida. Algumas pessoas, residentes em áreas de matas passaram a matar primatas por medo do contágio, presumindo que tal massacre e crime possuíssem a mesma eficácia quanto à vacina para prevenção. Contudo, ocorre que, ao contrário do que certas pessoas pensam, sabe-se que os macacos são atalaias e alertam para a ocorrência da doença. Quando infectados, adoecem e morrem, indicando que a febre amarela está na região. Ou seja, os humanos são tão vítimas quanto os macacos e não transmitem o vírus, pois o vetor é o mosquito.

Desde os primeiros indícios de civilização e, possivelmente, de sua existência, o homem convive com seres não-humanos. Logo, foi primordial que o homem se esvaecesse de si para que pudesse configurar permanência na divisão da natureza com outros animais. Ao decorrer das datas, a relação do homem com os outros seres vivos tem se contextualizado de forma objetificada. Por isso, é plausível se afastar da teoria civilista de coisificação dos animais, considerando os seres não-humanos como sujeito de direitos para frear os abusos diários que sofrem e impedir que indivíduos, baseados no desrespeito com os animais, ou até mesmo por falta de conhecimento e informação, como no caso da febre amarela, venha a cometer delitos sem qualquer motivação real.

O presente estudo pretende conscientizar os aplicadores do direito sobre o tema e desenvolver uma breve análise sobre surto de febre amarela e o aumento da matança de macacos, almejando a defesa dos direitos dos animais, pois tais como os humanos, têm também o direito à vida e a proteção, não devendo ser tratados como objetos, mas sim como "sujeito de direitos".

\section{METODOLOGIA}

O presente trabalho foi baseado em reflexões filosóficas, conteúdos históricos, leitura da legislação nacional, com abordagem hermenêutico-dialética. O método aplicado é o método hipotético-dedutivo, que por meio de uma hipótese, parte, por meio da dedução, para sua comprovação ou não.

\section{DIREITO AMBIENTAL COMO FONTE JURÍDICA ESPECÍFICA DE PROTEÇÃO AOS ANIMAIS}

O Direito tem como pressuposto garantir o exercício da cidadania para possibilitar a vida em sociedade e tem o papel de influenciar e interferir, direta ou indiretamente, o comportamento humano, seja por meio de leis coercitivas ou pela repressão pelo uso da força, monopólio do Estado, eis que para a preservação do direito individual é necessário a limitação da liberdade.

A tutela jurisdicional ganha maior proteção pela Carta Marta presumindo em seu artigo 225 que todos têm direito ao meio ambiente ecologicamente equilibrado, bem de uso comum do povo e essencial à sadia qualidade de vida, impondo à Coletividade e ao Poder Público a responsabilidade pela proteção ambiental e o dever de preservar e defender (ROS, MIRANTE e MORONG, 2017). Inclui-se também preservar a fauna e a flora e vedar as práticas que as coloquem em risco o meio ambiente, como previsto no "caput" e no inciso VII do mesmo documento jurídico.

A lei no 9.605 de 12 de fevereiro de 1998, conhecida como Lei dos Crimes Ambientais, assegura uma proteção mais específica à flora, fauna, recursos naturais e o patrimônio ambiental. Esta busca idealizar que toda violação a um direito é um crime, tendo como objeto a natureza (MORONG, 2014).

O artigo 32 da lei cima citada, prevê a pena de detenção, de três meses a um ano, e multa para quem praticar ato de abuso, maus-tratos, ferir ou mutilar animais silvestres, domésticos ou 
domesticados, nativos ou exóticos e, ainda, a pena é aumentada de um sexto a um terço, se ocorre morte do animal (MACHADO, 2014).

De outro lado, o Direito Ambiental também preza por respeito a um indivíduo, porém, compreendendo além da esfera privada para ter como amparo, em seu objetivo, a Natureza. Segundo Padilha (2010), é importante considerar a natureza não apenas como objeto de apropriação, como recurso para satisfação de desejos passível de uso indiscriminado pela lógica racionalista do mercado de produção e consumo, mas como agente que possui vida, um ser vivo, que, como todos os demais, está sujeito aos limites da morte; de uma continuidade subordinada ao tempo e ao cuidado, de uma preservação que exige responsabilidade e preocupação.

De fato, conforme destaca Benjamin (1996, p. 17), nos últimos anos, ganha força a tese de que um dos objetivos do Direito Ambiental é a proteção da biodiversidade, fauna e flora, sob uma diferente perspectiva: a natureza como titular de valor jurídico per se, inerente a si mesma, vale dizer, exigindo, por forças de profundos argumentos éticos, proteção independentemente de sua utilidade para o homem.

Reconhecer os direitos do seres não-humanos tem sido primordial para sustentar os movimentos que buscam disseminar a importância do respeito aos animais e repreender a ideia excêntrica dos seres humanos serem mais importantes. Assim, considera-se o valor em preservar o meio-ambiente não apenas em prol dos animais não-humanos, eis que, todavia, não apenas estes se beneficiam do ônus de viver na natureza, mas os seres humanos também. Logo, não há dúvida de que a preservação e proteção ambiental no geral transcende a defesa dos direitos dos animais como é visto no senso comum e atinge os direitos dos animais humanos.

\section{DA FEBRE AMARELA E O MACACO APENAS COMO HOSPEDEIRO}

Segundo Silvana Gomes Leal (2012) a febre amarela é uma doença não contagiosa que tem como vetor apenas o mosquito Haemagogus do gênero Sabethes, no modo silvestre. É certo que os seres humanos e os símios são somente hospedeiros, se não imunes, ou seja, não vacinados, podendo levar-se a óbito. Trata-se de matéria simples, mas que causa confusão em muitas pessoas leigas e residentes em áreas de mata, pois muitos antropoides tem sido mortos em prol de uma causa inexistente.

Os macacos, do mesmo modo que os humanos, são apenas hospedeiros do vírus. Logo, sacrificar a vida dos símios por hospedar o vírus é tão injustificável quanto seria se os humanos fossem assassinados por conta da doença. Portanto, somente o mosquito é transmissor e esse deve ser analisado. Importante também é destacar a necessidade da vacina, pois sem esta os hospedeiros não serão imunes e podem ser levados a óbito.

Por sua vez, o caso pode ser tratado com normalidade para o contato com os primatas, já que contrariamente às doenças infecciosas, as doenças contagiosas podem ser transmitidas artificialmente, por inoculação (LÖWY, 2006).

Denota-se que as doenças infecciosas, como é o caso da febre amarela, não podem ser transmitidas por vacinas e, por não serem contagiosas, pode haver contato entre os infectados.

Não há, sequer, respaldo ético-moral nos assassinatos, a não ser ignorância acerca do assunto. Por isso também, não se justifica a morte dos macacos.

\section{DO DIREITO À VIDA E A DESCOISIFICAÇÃO ANIMAL}

Diante de tal contexto é egrégio utilizar-se do conceito de senciência, utilizado muito na literatura para expressar a capacidade de um ser sentir dor e prazer, é peculiaridade dos animais conforme consta na ADI- Ação Direta em Inconstitucionalidade, 4.983. Destarte, a senciência é uma razão para que haja relevância para ratificar aos animais o não sofrimento.

Por isso, além de injustificada as mortes dos macacos, deve-se ser prezado os direitos de todo e qualquer animal, seja ele humano ou não, seu bem-estar, seu conforto, sua integridade 
corporal, de modo a não ser lesionado ou torturado, e defender o direito à vida como "sujeitosde-uma-vida" e sujeitos de direitos. Assim, os animais fazem jus tanto a preservação de suas vidas quanto de seus direitos, direito de existir e de manter sua completude física.

A corrente que tem como escopo tratar os animais em pretextos inseridos em viés utilitário precisa ser repensada através de uma extensão da ideia kantiana (Kant, 2004) de que os seres humanos devem ser tratados como um fim em si mesmos, nunca como um meio. Consequentemente, não são objetos a satisfazer nossos incessantes desejos, todavia seres com direito inerente à vida.

Costa Neto (2003) reitera que relegar o antropocentrismo excludente (é necessário) para partir do suposto de que a natureza encerra um valor transcendente à mera satisfação dos interesses e das necessidades do homem. Essa é a melhor vereda delineada por revigorados parâmetros de proteção ambiental.

Continua o autor explicando que essa nova forma de pensar o Direito Ambiental identificase com um holismo ético biocêntrico, mas depara-se com embaraços não suficientemente vencidos (NETO, 2003).

Tirar proveito dos animais como se fossem objetos para satisfazer nossos interesses parte do pressuposto utilitário de que muitos se satisfizerem com o prazeroso é pertinente, sendo que como Kant prega, nem sempre o quantitativo é o mais ético a ser praticado, pois ainda que muito se beneficiem o correto e moral é sempre preferível. E, ao reconhecer os direitos dos animais, pode-se sair de uma visão antropocêntrica para um viés mais empático com bases no direito natural - inerente e atemporal - para tutela de do direito a todos, inclusive os animais nãohumanos. "Afinal de contas, em que se fundamenta essa nossa dignidade, esse respeito que reivindicamos?" E mais: "Não seríamos, de um novo modo, racistas, os racistas da raça ou espécie humana?” (VALLS, 2004, p. 125-134).

Não há um ápice que fundamente o ser humano como supremo, e a Lei vem para garantir direitos já conquistados, de modo que a partir do momento que se distancia dessa responsabilidade, como pacto social, observações devem ser realizadas para a interpretação de que todos são iguais e socialmente relevantes. Os animais vão além de meros fantoches para obtenção de prazer ou preocupações infundadas, como no caso da febre amarela e os macacos. Homicídio é crime e assassinar animais é tão cruel quanto se fossem com humanos. Destarte, os direitos devem ser igualmente reconhecidos, independente de pertencer ou não à espécie humana.

De outro lado, é necessário que seja descontruído o status dos animais como objetos e além de uma questão doutrinária, jurisprudencial ou legislativa, é uma questão moral que exige ser superada e encontrada na História e na Filosofia, correntes ético-filosóficas que visem a inclusão dos animais como valores inerentes e intrínsecos a eles, no ordenamento jurídico.

O direito à vida, segundo Antônio Augusto Cançado Trindade (1993), é um princípio substantivo, em virtude do qual todo ser humano tem um direito inalienável a que sua vida seja respeitada, e um princípio processual segundo o qual nenhum ser humano haverá de ser privado arbitrariamente de sua vida.

Com efeito, comparando esse conceito em relação aos animais, percebe-se que nenhum ser vivo deverá ser privado arbitrariamente de sua vida.

Nesse sentido, é necessário afastar da teoria civilista de coisificação dos animais de modo a considerar os seres não-humanos como sujeito de direitos, para frear os abusos diários que sofrem e impedir que indivíduos, baseados no desrespeito com os animais, venha a cometer delitos sem qualquer motivação real.

Os humanos são diferentes dos animais não-humanos por idiossincrasia fisio-anatômicas, entretanto iguais por ambos possuírem a vida. Portanto, devem ser descoisificados e tratados com dignidade. Ademais, ressalta-se a importância de sugerir mudanças à legislação atual em relação 
ao status jurídico dos animais, devendo ser tratados como "sujeitos-de-direitos", personificados devido à senciência e, por serem portadores de uma vida, merecem que esta seja tutelada.

\section{CONCLUSÃO}

Os animais, do mesmo modo que os humanos, seres vivos, fazem jus ao direito natural de ter, em termos constitucionais, seu maior bem jurídico tutelado, ou seja, sua vida resguardada. Não cabe aos seres humanos decidir pelos seres não-humanos como se tivessem o direito de decidir pela vida de um outro ser existente, sendo que cada indivíduo possui apenas liberdade para com sua própria propriedade, nesse caso a vida.

Apesar de o Brasil ser dotado de uma legislação ambiental com um posicionamento mais inclusivo aos animais, seja na Constituição ou em leis específicas como a Lei de Crimes Ambientais, ainda há uma cultura enraizada na sociedade atual de que o ser humano é uma criação divina e somente sua vida merece guarida da legislação. Além disso, acredita a sociedade que os animais foram criados, única e exclusivamente, para servirem os seres humanos, com a conotação de escravo. Acaba, por sua vez, criando leis com bases em teorias como a civilista de coisificação dos animais, na ideia de que estes são propriedades. Assim, é certo que o ordenamento jurídico atual necessita de alterações a fim de não considerar os animais como mero bens móveis.

Por sua vez, a febre amarela é uma doença não contagiosa que tem como único vetor o mosquito Haemagogus Sabethes, sendo os seres humanos e os macacos somente hospedeiros. Portanto, os símios não transmitem a doença e, se não imunes, adoecessem e podem morrer. Por isso, as mortes desses não são justificáveis.

De outro lado, os seres não-humanos são dotados de senciência, não podendo ser considerados propriedades. A cada ser vivo deve ser concedido o direito à vida e a integridade corporal.

Conclui-se que, por ser a referida doença infecciosa causada por um flavírus e ser transmitida em áreas florestais, principalmente pelo mosquito Haemagogus, os direitos dos macacos devem ser tutelados, eis que não são responsáveis diretos pelo contágio e, tais como os humanos, têm também o direito à vida, pois eles são sujeito de direitos e seus direitos são deveres dos indivíduos.

\section{REFERÊNCIAS}

BENJAMIN, A. H. V. Os Objectivos do Direito Ambiental. In Lusiada - Revista de Ciência e Cultura. Série de Direito, Número Especial. Porto: Invulgar - Artes Gráficas Ltda., 1996.

BRASIL. Ação Direta de Inconstitucionalidade, Ceará, número 4.983. Relator: Ministro Marco Aurélio de 06/10/2016. STJ, 2016.

BRASIL. Lei no 9.605, de 12 de fevereiro de 1998. Dispõe sobre as sanções penais e administrativas derivadas de condutas e atividades lesivas ao meio ambiente, e dá outras providências. Diário Oficial da União, Brasília, 13 fev. 1998. Disponível em: < http://www.planalto.gov.br/ccivil_03/LEIS/L9605.htm>. Acesso em: 10 ago. 2018.

COSTA NETO, N. D. C. Proteção Jurídica do Meio Ambiente, 1 ed., Belo Horizonte: Del Rey: 2003.

KANT, Immanuel. Fundamentação da metafísica dos costumes e outros escritos; tradução de Leopoldo Holzbach - São Paulo: Martin Claret, 2004.

LÖWY, I. Vírus, mosquitos e modernidade: a febre amarela no Brasil entre ciência e política [online]. Tradução de Irene Ernest Dias. Rio de Janeiro: Editora FIOCRUZ, 2006. 
LEAL, S. G. Infectologia - óptica da saúde: febre amarela, 1 ed., Brasília: Universidade de Brasília, 2012.

MACHADO, P. A. L. Direito Ambiental Brasileiro. 22a ed. São Paulo: Malheiro, 2014.

MORONG, F. F. El régimen jurídico de las licencias y autorizaciones ambientales en España y Brasil: análisis jurídico-ambiental derivado de los aspectos novedosos de la normativa general de laUniónEuropea sobre prevención y control integrados de lacontaminación. 1. ed. Salamanca: EdicionesUniversidad de Salamanca, 2014.

PADILHA, N. S. Fundamentos Constitucionais do Direito Ambiental Brasileiro, 1 ed., Rio de Janeiro: Elsevier, 2010.

ROS, L. N.; MIRANTE, M. H. P. MORONG, F. F. O direito ambiental e a geografia no Pontal do Paranapanema: Marabá Paulista e Presidente Venceslau-SP. Colloquium Socialis, Presidente Prudente, v. 01, n. Especial 2, Jul/Dez, 2017, p.333-339. DOI:z10.5747/cs.2017.v01.nesp2.s0157 Disponível em: <http://www.epublicacoes.uerj.br/index.php/geouerj/article/viewFile/1389/1179>. Acesso em: 10 ago. 2017.

SCHOPENHAUER, A. Da metafísica do amor e da metafísica da morte, 1 ed., São Paulo: Martins Fontes, 2000.

SILVA, Caio Mário da. Instituições de direito civil. v.1. Rio de Janeiro: Forense, 2005.

TORRES, Leonardo Araújo; TORRES, Rodrigo Araújo. Direito Ambiental brasileiro: surgimento, conceito e hermenêutica . Revista Jus Navigandi, ISSN 1518-4862, Teresina, ano 17, n. 3248, 23 maio 2012. Disponível em: <https://jus.com.br/artigos/21836>. Acesso em: 10 abr. 2017.

TRINDADE, A. A. C. Direitos Humanos e Meio Ambiente: paralelo dos Sistemas de Proteção Internacional. Porto Alegre: Sergio Antonio Fabris Editor, 1993.

VALLS, Á.L.M. 2004. Sobre a humanização. Palestra proferida no 2 o Congresso do Conesul de Negócios e Gestão de Saúde, realizado no ano de 1988 em Porto Alegre e, posteriormente, publicada em texto intitulado "O respeito à pessoa humana". In: Á.L.M. VALLS, Da ética à bioética. Petrópolis, Vozes. 